
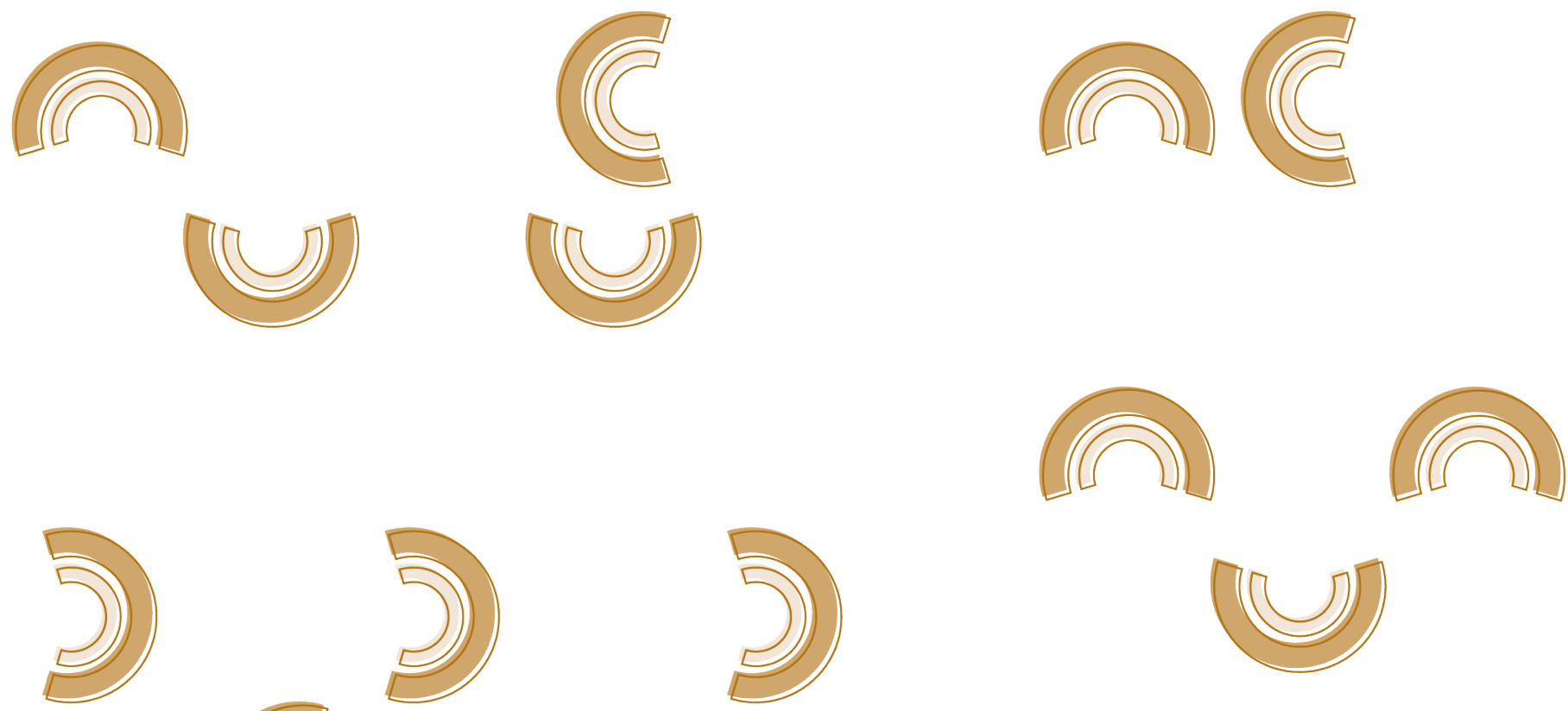

Dossiê Dramaturgia Da DANÇA

\title{
A Tessitura dos Mestres
}

\section{Tarcísio dos Santos Ramos}

Bailarino, diretor e dramaturgista. Mestre em Artes (EBA/UFMG), professor de Técnicas Corporais do Teatro Universitário da UFMC e doutorando do Programa de Pós-Graduação em Artes da Escola de Belas Artes (UFMG/ 2015-2019) onde realiza a pesquisa TRANSFORMA - CENTRO DE DANÇA CONTEMPORÂNEA

- Uma Poética para a Formação, sob a orientação do Prof. Dr. Arnaldo Leite de Alvarenga, tendo as Artes da Cena como linha de Pesquisa. 


\section{RESUMO}

Neste artigo apresento um panorama sobre a dramaturgia em dança sob o ponto de vista histórico, a partir dos bailarinos, diretores e coreógrafos alemães que compuseram a base da dança expressionista alemã e da dança-teatro e, ainda, daqueles que contribuíram para a criação da dança moderna americana. Esses artistas estabeleceram novas formas do pensar e fazer a dança, principalmente na perspectiva da história da dança moderna. Logo perceberemos que não só de rupturas o percurso histórico se faz, mas também de influências e continuidades. Assim, ao longo da história é perceptível que temos um passado, ainda que o presente possa modificá-lo, configurando um presente-futuro modificado e ampliado.

Palavras-chave: Dramaturgia. Dança Expressionista. Dança-Teatro. Dança Moderna Americana.

\section{ABSTRACT}

In this article I introduce a panorama of dance dramaturgy from a historical point of view, considering German dancers, directors, and choreographers who were responsible for establishing the basis of German expressionist dance and dance-theater and, furthermore, those who contributed to the creation of American modern dance. These artists established new ways of thinking and doing dance, mainly seen from the perspective of modern dance history. We may soon perceive that such historical path is not only made of ruptures, but also of influences and continuity. Thus, it is possible to notice that throughout history we have had a past, even though the present may modify it, shaping a modified and expanded future-present.

Keywords: Dramaturgy. Expressionist Dance. Dance-theater. American Modern Dance. 


\section{INTRODUÇÃO}

Esta escrita é uma das partes de minha dissertação de mestrado nominada $\mathbf{A}$ TECELAGEM DAS MARGENS POR QUE TÃO SOLO? Dança e dramaturgia. A dissertação, defendida em 2008 na Escola de Belas Artes da Universidade Federal de Minas Gerais tinha como proposta investigar a dramaturgia do espetáculo Por que tão solo? (Prêmio de dança Klauss Vianna/ Funarte/2006). A partir dessa investigação me debrucei sob os diversos aspectos, características e mecanismos criativos para elencar os elementos que constituíam a dramaturgia do espetáculo. Para tanto, investiguei os procedimentos da dramaturgia contemporânea voltada para a conexão entre a dança e o teatro. Mas, antes disso, percebi a necessidade de conhecer como a dramaturgia era vista e poderia ter sido pensada pelos criadores a partir do século XVIII (JeanGeorges Noverre). Nesta adaptação, opto por re-traçar um panorama a partir dos bailarinos, diretores e coreógrafos alemães que compuseram a base da dança expressionista alemã e da dança-teatro (Isadora Duncan, Rudolf Laban, Mary Wigman, Kurt Jooss e Pina Bausch) e, ainda, daqueles que contribuíram para a criação da dança moderna americana (François Delsarte, Marta Graham, Doris Humphrey e Merce Cunningham). A intenção aqui é valorizar aqueles que vieram antes de nós revelando que a dramaturgia não era somente um elemento do teatro e que a dança trouxe uma contribuição relevante para que a mesma fosse pensada, nos dias hoje, de maneira ampliada.

\section{O EXPRESSIONISMO ALEMÃO - TESSITURA VISCERAL}

Podemos detectar impulsos expressionistas em praticamente todos os tipos de atividades artísticas. Pode-se falar em filósofos expressionistas, historiadores da arte expressionistas e trabalhos de crítica que se encaixam nesse movimento. Vale ainda observar que muitos artistas expressionistas envol- 
veram-se com mais de uma forma de expressão, o que reforça a versatilidade desse movimento. Encontramos pintores que falam de seu trabalho em termos musicais ou poetas que, segundo Cardinal, investem pesadamente no simbolismo das cores. De acordo com esse autor:

Foi sem dúvida um movimento de muita dinamicidade, a ponto de, ao liberar energias de forma tão febril, criar uma impressão inicial de caos absoluto. O Expressionismo nada mais é que uma prospecção de estados fronteiriços e posições extremas, que freqüentemente implicam crises de indecisão e gestos hiperbólicos dirigidos simultaneamente postular que a agonia é uma forma de êxtase. E o êxtase uma forma de agonia. Alegria e depressão, atração e repulsão, delicadeza e brutalidade, harmonia e tumulto, são apenas algumas antíteses incorporadas em seus argumentos ou atos criativos. Os expressionistas podem ser obcecados pela vida urbana e, mesmo em direções contrárias. Por vezes, os expressionistas parecem assim, ansiaram por uma vida campestre. Consideram a individualidade como valor supremo, e apesar disso, demonstram um notável entusiasmo pela ação coletiva. Alimentam-se de sensações, embora busquem a dimensão supra sensória da experiência (CARDINAL, 1984, p. 17).

A dança ocupa um lugar especial dentro do movimento expressionista, sendo reconhecida como o veículo natural deste, pois, para Cardinal, "ela implica impulsos de uma única sensibilidade definindo seu próprio espaço expressivo" (1984, p. 56).

O Expressionismo nos oferece elementos e características que julgo determinantes e essenciais para uma construção dramatúrgica. Dentre eles estão o sentimento, o impulso, a intenção, a intensidade das emoções e a recepção. Verificaremos agora como esses elementos são trabalhados por construtores que atuaram dentro do universo da dança expressionista.

ISADORA DUNCAN - Mitologia PESSOAL, LIBERDADE E REVOlUÇÃo (...) Mas agora, para render graças a Afrodite, olhai-a. Não é ela de repente uma verdadeira onda do mar? Ora mais pesada, ora mais leve que seu corpo, ela salta, como chocar-se num rochedo; tomba molemente...é a onda! (Paul Valéry)

Embora tenha nascido em São Francisco, no final do século XIX, mais precisamente em 1878, Isadora é reconhecida como precursora da dança expres- 
sionista alemã, devido a sua emigração para Berlim. Ela funda sua escola em um subúrbio dessa cidade, no início do século XX. Segundo Cardinal, Duncan:

(...) executava uma sequência de movimentos que se desenvolviam espontaneamente em resposta a impulsos internos, imprevisíveis e derivados de suas fontes espirituais e emocionais (CARDINAL, 1994, p. 29).

Mais do que a técnica, Isadora agrega a vida em sua dança, dançando suas alegrias e emoções e seus pressentimentos, ainda que obscuros. Ela pretendia e perseguia uma revolução para os homens e acreditava que poderia, através de sua dança, "(...) exprimir os sentimentos e as emoções da humanidade" (GARAUDY, 1973, p. 58).

Assim, Isadora tem na natureza a inspiração para realizar suas danças, rompendo convenções acadêmicas. Aproximando-se da natureza, Isadora encontra o ritmo (movimento de fundo) como princípio ordenador de sua dramaturgia. Como ela mesma nos diz:

Minha ideia do movimento de dança veio do ritmo das ondas... Eu tentava seguir seus movimentos e dançar em seu ritmo (GARAUDY, 1973, p. 58).

Isadora encontra ainda outros elementos norteadores para construir suas danças. Preocupa-se com outra constituição lógica. A dançarina abomina a pantomima, que, segundo ela, afastava a dança de seu caráter transcendente. Verificamos aí que o caráter transcendente, para Duncan, vai além da necessidade de traduzir a dança como palavra, daí sua recusa pela pantomima, que, para ela, "era um substituto da palavra" (GARAUDY, 1973, p. 70).

Assim, percebemos que há rupturas e também continuidades no pensamento sobre o texto dançante. A dança é vista por Duncan como algo que se organiza em torno do movimento e não em torno da palavra, do verbo, tendo no ritmo sua inspiração e fluência. Interessante notar que Isadora repete e enfatiza alguns preceitos do mestre francês Jean-Georges Noverre (séc. XVIII) ao concordar que a dança possui um poder de comunicação e comunhão, que ela deveria ser expressiva, e que deveria ser "a expressão divina do espírito humano pelos movimentos do corpo". O exercício da escuta como orientador da dramaturgia também retorna aqui, quando Isadora, desejando reencontrar ritmos inatos do ser, propõe, segundo Paul Bourcier, "escutar as pulsações da terra, obedecer à lei de gravitação, feita de atrações e repulsas, de atrações e resistências" (2001, p. 248).

Duncan dialogava com filósofos, com pinturas gregas "dançantes", com os Deuses, com a chamada "grande" música, com a tragédia, com as nuvens, o vento, 
o mar e as árvores. Ouvia seu interior e a ele confiava a ação de mover-se. A respeito das muitas vozes que se manifestavam em seu interior, Isadora nos relata:

Minha alma era um campo de batalha onde Apolo, Dionísio, Cristo, Nietzche e Richard Wagner disputavam terreno uns aos outros (apud GARAUDY, 1973, p. 62).

Como dançarina dionisíaca mística, irreverente, trágica ou flutuante, Isadora apontou e abriu caminhos com seus pés nus e seus braços de nuvem, com seu corpo de árvore ou de mar. Dançando sua vida, ela nos orienta para uma dramaturgia que só pode ser traçada com base na própria vida do artista criador, ancorada em elementos como o ritmo, as pulsações e, sobretudo, a liberdade de movimento. Uma dramaturgia que revela o íntimo do bailarino e permite que seus desejos, suas aspirações, bem como decepções e frustrações se transformem em material que não só alimenta, mas também orienta e ordena suas danças. É a experiência humana no coração da criação. Em Duncan, a dança faz da mecânica somente um meio para atingir seus objetivos, e não um fim em si mesma.

Entre maio e junho de 1901, Isadora Duncan, segundo Bergsohn e Bergsohn (2003, p. 3), apresentou-se em Paris. Sobre sua atuação, um jovem artista, na época ainda envolvido com shows de cabaré e clubes noturnos, escreveu:

A principal contribuição de Duncan foi, contudo, que ela redespertou a forma expressiva da dança, que poderia ser chamada de dança-lírica, em contraste com as principais formas dramáticas do ballet ${ }^{1}$.

Esse jovem artista viria a se tornar, posteriormente, um dos maiores estudiosos do movimento dentro e fora da dança. Seu nome:

\section{RUDOLF VON LABAN - A LIFE FOR DANCE ${ }^{2}$}

Ela se transforma em dança, e se consagra toda ao movimento total! (Paul Valéry)

Nascido no coração do Império austro-húngaro, Rudolf von Laban (1879-1958) foi o fundador da dança expressionista. Ele era fascinado pela diversidade de danças, culturas, expressões e movimentos corporais. Mesmo sendo filho de um oficial militar que queria seu alistamento nas forças armadas, Laban preferiu a vida boêmia, a pintura em vez da guerra. Estudou durante sete anos na escola de Belas Artes de Paris e Munique, e lá descobriu que sua verdadeira vocação era o espetáculo, sobretudo, o espetáculo dançado, acabando por
1 "The main achievement of Duncan was, however, that she reawakened a form of dance-expression, which could be called dance-lyrics, in contrast to the mainly dramatic dance forms of the ballet".

2 Uma vida para a dança. Frase gravada na pedra tumular de Rudolf von Laban. 
montar uma revista com dançarinos do Moulin-Rouge. Depois de estudar em Paris, retornou a Viena numa época em que o Império estava prestes a ruir.

Toda a experiência de Laban termina por conduzir a um retorno à natureza, a um corpo livre e saudável, assim se dá no caso de Duncan - corpo-dança: livre de repressões. Laban cria e define estruturas do movimento, atentando-se para quatro fatores que seriam seu alicerce: espaço, tempo, peso e fluência. Ele devolve ao espaço sua profundidade. Um corpo atuando em um espaço móvel, dentro de um volume e em várias direções, e liberta-se da música e de sua métrica. Peso determina dinâmica, equilíbrio e desequilíbrio. Enfim, Laban liberta o movimento de qualquer restrição, o que permite a percepção da afinidade de suas ideias com as de um dos grupos precursores do Expressionismo: O Cavaleiro Azul, que postulava "a harmonia total entre alma e espírito através do movimento".

Laban cria a "labanotação" - labanotation - método que permite a leitura de coreografias através de partituras. O método possui princípios básicos, simples e claros: divisão do espaço em três níveis (vertical, horizontal e axial) sobre os quais se inscrevem doze direções de movimentos.

Talvez possamos afirmar que Laban está para a dança assim como o mestre russo Stanislásvski está para o teatro: pesquisadores incansáveis que dedicaram suas vidas à observação e à reflexão, à prática artística e ao registro de suas teorias. Como nos lembram Hodgson e Preston-Dunlop:

Resumindo a respeito de sua contribuição, ele simplesmente declara ter devotado toda sua vida em pesquisar a natureza, significado e ramificações do movimento, mas o fato que ele era capaz de transferir todo o seu entendimento sobre coreografia, dança, indústria, interpretação, educação, terapia, conselheiro vocacional, linguagem corporal e o treinamento de artistas de teatro é apenas uma pequena indicação de uma totalidade de descobertas de suas teorias universalmente notáveis (HODGSON; PRESTON-DUNLOP, 1990, p. 20)

Apresentaremos a seguir aspectos do pensamento de Rudolf Laban que possibilitam a ampliação de nossa reflexão.

\section{OS FATORES DO MOVIMENTO}

Independentemente do que um criador de dança escolha como tema, ideia ou objeto para criar e desenvolver sua obra, ele terá sempre dois propósitos: expressar e comunicar. Segundo Laban, a dança deveria se comprometer com a expressão de uma ideia e exigiria uma grande dose de concentração para 
expressar-se. Uma expressão materializada em uma forma plena de qualidades. Já não nos perguntamos agora por que nos movemos? Nem o que nos move? Torna-se urgente interrogar-nos como nos movemos?

Um sentido. Estamos sempre buscando um sentido ao assistirmos um espetáculo. Podemos não dar importância ao fato de termos ou não entendido uma obra, mas considerando fundamental que ela nos traduza algum sentido. Algo parecido acontece quando vemos uma cor e percebemos a sensação de agressividade ou passividade que nos é transmitida por ela. Assim ocorre ao vermos um espetáculo de dança. Na maioria das vezes não capturamos seu sentido pelos filtros da razão, e sim pelas vias da percepção. O movimento pode nos traduzir sensações, emoções, vibrações e podemos até traçar uma narrativa para o mesmo, mas a percepção deste se amplifica livremente dentro de cada espectador, pois, de acordo com o próprio Laban: “(...) há também valores intangíveis que inspiram movimentos" (1971, p. 19).

Reforçando o pensamento labaniano, é mais uma vez o filósofo Roger Garaudy que nos elucida sobre o processo de comunicação e recepção diante do movimento. Vejamos:

Toda dança implica participação, mesmo quando ela é espetáculo, não é apenas com os olhos que a "acompanhamos", mas com os movimentos pelo menos esboçados de nosso corpo. A dança mobiliza, de algum modo, um certo sentido, pelo qual temos consciência da posição e da tensão de nossos músculos. (...) Este sexto sentido estabelece, graças a um fenômeno de ressonância ou de simpatia muscular, o contato entre o dançarino e o participante (GARAUDY, 1980, p. 21).

Assim, o espectador capta a dança através de sua própria musculatura e de seus sentidos: olhos, ouvidos, pele, cheiro, etc. De um lado a dança, de outro, o espectador. Existe entre uma e outro um espaço que há de ser preenchido. Esse espaço é reconhecido por Laban como uma "corrente magnética bipolar" (1971, p. 27), estabelecida entre palco e plateia. O preenchimento desse espaço pode se dar de diversas formas e, ao pensarmos a dramaturgia da dança, poderemos encontrar, nela, uma possibilidade de ocupar tal espaço, fazendo com que a mesma possibilite e contribua para a conexão entre esses dois polos.

A dança começa com a revelação de uma "ideia" que lhe inspirou a existência. O próximo passo para que essa ideia comece a se instalar surgirá através das atitudes internas do atuante em relação aos fatores de movimento, fazendo com que o esforço seja um orientador de sua movimentação. Conforme registrado por Rengel em seu Dicionário Laban, "esforço é o ritmo dinâmico 
do movimento do agente (...) e que comunica a qualidade expressiva do movimento" (RENGEL, 2003, p. 60-61).

Ainda segundo a autora, Laban também usa o termo antrieb = propulsão, impulso, ímpeto. Se considerarmos que o esforço traz a qualidade expressiva do bailarino, caberia ao dramaturgista, por sua vez, atentar para as formas de articular essas qualidades durante a criação e o desenvolvimento do movimento-dança. Para além da análise dos esforços, o ritmo a ser desenvolvido se tornará protagonista no próximo momento da construção. Nas palavras de Garaudy: "Laban observa que o ritmo é, ele próprio, uma linguagem particular que pode veicular significado sem recorrer às palavras" (GARAUDY, 1980, p. 114).

Os fatores de movimento observados e definidos por Laban podem ser um primeiro indicativo na construção da dramaturgia do movimento dançado. Sem dúvida, toda execução, consciente da utilização desses fatores e das qualidades adequadas de esforço geradas pelos mesmos, poderá causar maior aproximação ou distanciamento entre executor e receptor. A escuta dos impulsos durante a construção da tessitura dramatúrgica é de suma importância, pois estes, que a princípio parecem desordenados, podem, à medida que o trabalho se desenvolve, regular e equilibrar movimentações e qualidades de expressão. Ao dramaturgista cabe perceber, escolher e articular as qualidades de esforço, também reconhecidas com o intuito de atingir um objetivo proposto, pois:

Um único movimento, ou uma sequência de movimentos, deve revelar, ao mesmo tempo, o caráter de quem o realiza, o fim pretendido, os obstáculos exteriores e os conflitos interiores que nascem deste esforço (GARAUDY, 1980, p. 113).

Von Laban orienta seu trabalho para os fatores de movimento, que também podem ser vistos como um exercício de circulação, em que cada elemento interage e dialoga com o outro. Muitas vezes um nasce do outro, de uma necessidade indicada por uma qualidade de esforço, pois, para Laban, movimentamo-nos para satisfazer uma necessidade.

\section{DANÇA-DRAMA / DiÁLOgo E FRONTEIRA}

Von Laban não só se aproximou do teatro na infância e na adolescência, mas também durante toda a sua vida dedicou-se ao treinamento de atores. Ele dava a mesma importância ao corpo, seja no teatro ou na dança, como instrumento total, valorizando as peculiaridades de cada indivíduo e suas características de esforço. Sabia que essas características eram únicas e que os movimentos de um indivíduo iriam mostrar os efeitos de seu meio e de sua 
hereditariedade artística. Laban abarcou durante sua pesquisa e criação de todo tipo de estilo em seu repertório. Segundo Dunlop: "Linha narrativa e padrões abstratos, comédia, tragédia, histórias, sátiras, burlescos - Tudo apareceu dentro de seu repertório" (DUNLOP, 1990, p. 26). ${ }^{3}$

Ao observarmos danças de 1923 a 1928, percebemos como o elemento dramático é constante, enfatizando o encontro com a teatralidade em sua expressão. Como nos informa Rengel $(2003,42)$ :

Dança-teatro ou dança de palco, termos usados por Laban com o mesmo significado. Em alemão, tansbühne. Dança-teatro é fusão do movimento, da música e da palavra falada. Uma forma de dança usada por Laban como tentativa de "intensificação formal da expressividade humana (MARY WIGMAN, 1921 apud PRESTON, 1995).

O termo "dança-teatro" ganharia mais propriedade com o aluno e colaborador de Laban, Kurt Jooss, e posteriormente seria totalmente consolidado por uma discípula de Jooss: Pina Bausch, como veremos mais adiante. Gostaria, porém, de chamar atenção para uma afirmação de Laban que nos leva a uma reflexão que julgo pertinente:

Representações teatrais onde os elementos pictóricos do cenário e as naturezas mortas são superenfatizadas tendem a enfraquecer o interesse dinâmico, que é o elemento todo-poderoso (LABAN, 1971, p. 31).

Se considerarmos a hipótese de que um acontecimento dinâmico tem sua força na organização dinâmica dos movimentos, como fator poderoso da expressão cênica, poderíamos suspeitar que a mesma pudesse também nos orientar para a construção de uma dramaturgia. De acordo com Rengel:

Dinâmica refere-se à combinação das qualidades de esforço. Dependendo da escolha das qualidades, é gerada um tipo de dinâmica. (...) Dinâmica é a resultante expressiva do movimento quando duas ou mais qualidades de esforço se organizam simultaneamente (RENGEL, 2005, p. 44).

Os movimentos dançantes, ao entrarem em diálogo com outras artes, não estariam criando uma nova dinâmica como fruto desse encontro? Assim, poderia a escuta e a tessitura das dinâmicas geradas pelos movimentos dançantes ser parte do fio condutor de uma dramaturgia? Para Laban, "o que realmente acontece no teatro não se dá apenas no palco ou na platéia, mas no
3 Narrative line and abstract pattern comedy, tragedy, history, satire, burlesque - all appeared within his repertoire. 
âmbito de uma corrente magnética entre esses dois pólos" (1971, p. 26). Laban irá se referir posteriormente aos impulsos internos que irão ajudar a estabelecer esse contato e complementa trazendo à tona o caráter dinâmico como elemento essencial à representação.

Esse elemento "todo poderoso" referido por von Laban é também reconhecido por Rudolph Arnheim, que se surpreende como o fato de que teóricos e pesquisadores lhe atribuíssem pouco valor:

Considerando que a dinâmica é a própria essência da experiência perceptiva e assim prontamente reconhecida por poetas, artistas e críticos, é de se notar que teóricos e pesquisadores lhe tenham dado tão pouca atenção (ARNHEIM, 2005, p. 409)

Arnheim complementa sua argumentação ao revelar, ainda, que:

A natureza dinâmica da experiência sinestésica é a chave para a surpreendente correspondência entre o que o dançarino cria com suas sensações musculares e a imagem do corpo vista pelo público. A qualidade dinâmica é o que unifica os dois diferentes meios (ARNHEIM, 2005, p. 398).

Tomada como fator responsável por dar nexos e circulação de sentido ao movimento dançado e como tecedora das ações teatrais, a dramaturgia se torna, aqui, um elemento também responsável por realizar a ponte entre esses dois pólos - palco e plateia -, através da percepção e da articulação das dinâmicas criadas dentro dessa zona de encontro e diálogo.

Assim, a dinâmica de ações que dançam ou dos corpos idílicos que atuam será também ressignificada, criando uma nova dimensão sinestésica para o intérprete e o espectador, bem como entre os mesmos. Cabe ao dramaturgista não somente fazer com que essa dramaturgia que une margens seja tecida com foco nas ações ou nos fluxos de movimento, mas também estar atento à tessitura das dinâmicas resultantes desse encontro. Ele deve perceber e equilibrar identidades que ora amalgamam-se, ora colidem ou traçam seus cursos lado a lado, fazendo com que esse intervalo venha à luz. Mais uma vez, é Arnheim que nos apresenta a dinâmica como um núcleo gerador de sentido:

Finalmente, é essencial para a execução do dançarino e do ator que a dinâmica visual seja claramente separada da mera locomoção. Eu percebo que o movimento parece morto quando dá a impressão de mero deslocamento. É claro que fisicamente todos os movimentos são causados pela mesma espécie de força, mas o que conta para a execução artística é a dinâmica trans- 
mitida ao público visualmente, porque apenas a dinâmica é responsável pela expressão e significado (ARNHEIM, 2005, p. 399).
Assim, por meio da união entre música, palavra e movimento, Laban nos oferece uma dramaturgia cujos elementos são os próprios fatores do movimento pesquisados e desenvolvidos por ele, terminando por gerar uma dramaturgia com base na escuta e na percepção das dinâmicas.

\section{MARY WIGMAN - A ESSÊNCIA EXPRESSIONISTA E A FORMATAÇÃO} DO CAOS

“- Coisa nenhuma, caro Fedro. Mas qualquer coisa, Erixímaco. Tanto o amor quanto o mar, e a própria vida e os pensamentos... Não sentis que ela é o ato puro das metamoforses?" (Paul Valéry)

O expressionismo caracteriza-se basicamente pela expressão de impulsos interiores do ser humano (violentos, no caso de Wigman), revelando necessidades urgentes, transformadas em movimentos vitais. Esses impulsos tinham como base uma grande concentração e, quando ordenados, demonstravam grande poder de expressão. Mary Wigman (1886-1973) embasou sua dança nesses impulsos internos, permitindo ao bailarino expressar-se através de uma grande liberdade individual, calcada a princípio na percepção de seus instintos, para só posteriormente formatá-los tecnicamente. Assim, poderíamos dizer que, se Laban libertou a dança, Mary Wigman libertou o dançarino. Dentre os dançarinos expressionistas, ninguém mais do que Wigman sentiu e materializou a presença do trágico, da angústia e do dilaceramento em suas danças. Todos esses sentimentos nasceram como fruto de sua convivência e sobrevivência durante o período em que o mundo passou por duas grandes guerras mundiais, que tiveram a Alemanha como protagonista do conflito. Wigman era essencialmente germânica, e como ela mesma nos diz ao reconhecer o seu fazer em suas origens: "Meu país, minha língua, meus sentimentos, pensamentos, minha dança" (ver referência em bibliografia/filmes).

Luz e trevas, Apolo e Dionísio, artes plásticas (máscaras) e literatura, demônios e divindades, violência e paixão, êxtase e forma, repugnação e fascínio - esses são os diálogos em que a bailarina, professora e coreógrafa se lança. Em suma, diálogos entre vida e morte.

Após desvincular-se de Dalcroze ${ }^{4}$, Wigman, aconselhada por Emil Nolde que exerce grande influência em sua vida, procura por Laban, com quem acaba por estabelecer uma fascinante identificação. Assim, Wigman tornou-se amiga e assistente de Laban entre os anos de 1913 a 1919. Ambos sofriam in-
4 "Compositor e professor de música nascido na Áustria e naturalizado suíço em 1865, desenvolveu um sistema de treinamento da sensibilidade musical que foi denominado eurritmia, baseado no movimento rítmico. (...) Entre seus discípulos de enorme importância podemos citar Mary Wigman e Ivone Georgi" (CAMINADA, 1999, p. 203).

5 Emil Nolde (1867-1956), cujo verdadeiro nome era Emil Hansen, foi um dos mais importantes pintores expressionistas alemães. Os seus quadros, tal como pretendia, chocavam o espectador, devido à vivacidade das cores, que contrastavam abusivamente umas com as outras, à deformação dos rostos das personagens retratadas, à distorção das perspectivas e ao excessivo uso de tinta. 
fluências dos dadaístas ${ }^{6}$ e faziam parte do grupo de artistas que frequentavam o movimento. No ano de 1920, rompe agressivamente com Laban e o deixa, seguindo para uma carreira solo. Ela não acreditava que o balé clássico e a dança moderna poderiam conviver dentro de uma mesma estrutura de formação e expressão do dançarino. Fazendo do trágico, do êxtase e da morte motivos de inspiração e diálogo para criar e desenvolver suas danças, Wigman vem reforçar, mais uma vez, a construção de uma dramaturgia com base na escuta das pulsões e dos sentimentos como norteadores da criação e da composição. A liberdade creditada aos bailarinos faz com que estes entrem em contato com suas pulsões mais obscuras, das quais o movimento deveria emergir, ser "explodido" e lançado para fora do corpo. Tessitura de explosões arrebatadoras e dilacerantes traduzidas em uma dança de elementos dramáticos que dialogavam, sobretudo, com a morte - assim era a dramaturgia de Wigman. A crença em seu fazer lhe garantiu o direito à vida, ainda que atingisse uma forma "degenerada", como seus conterrâneos nazistas chegaram a afirmar.

\section{Kurt Jooss - O NOVO "BALÉ DE AÇÃo"}

Seus olhos voltaram à luz. (Paul Valéry)

Tendo crescido em um lar onde música e teatro se faziam presentes em larga escala, o jovem Kurt Jooss (1901-1979), revelou-se desde cedo um garoto talentoso (tocava piano e realizava experimentos coreográficos). Foi através da dança que ele encontrou respostas para suas insatisfações. O encontro com Laban foi determinante em sua vida, levando-o a superar a dúvida entre se dedicar aos negócios da família (no caso, a agricultura) ou à dança e a decidir-se definitivamente pela profissão de dançarino. Em seu depoimento, podemos observar o poder entusiástico que a dança exerceu sobre ele, ao "visitá-lo" e envolvê-lo completamente. Vejamos: "A dança, pela qual, eu me mostrava desatento, veio até mim, e eu fui um ser adormecido que despertou com a brilhante luz do sol da manhã" (apud BERGSOHN; BERGSOHN, 2003, p. 17).

Do o ponto de vista labaniano, ainda segundo os autores citados acima, "Jooss apareceu na hora certa. Ele era exatamente o que Laban precisava, uma pessoa que poderia conservar todo material que Laban havia formulado"s (BERGSOHN; BERGSOHN, 2003, p. 19).

Jooss teve uma rápida ascensão no mundo da dança, tanto como bailarino, quanto como pedagogo e diretor-coreógrafo. Em 1927, ele foi convidado a dirigir o departamento de dança da Folkwang School, que seguia as idéias de Laban, ou seja, a combinação entre palavra, dança e música. Aliando elementos do balé clássico com a dinâmica e a expressividade da dança moder-
6 O movimento Dada ou Dadaísmo foi uma vanguarda moderna fundada em Zurique, em 1916, por um grupo de escritores e artista plásticos. $\mathrm{O}$

Dadaísmo é caracterizado pela oposição a qualquer tipo de equilíbrio, pela combinação de pessimismo irônico e ingenuidade radical, pelo ceticismo absoluto e improvisação. Enfatizou o lógico e o absurdo (...) Sua principal estratégia era mesmo denunciar e escandalizar.

7 "(...) The dance, of which I was unaware, came to me, and I was one sleeping being awakened by bright morning sunlight".

8 "Jooss came along at just the right time. He was exactly Laban needed, a person who could retain all the material that Laban had formulated". 
na, ele abre espaço para o diálogo com outras artes, principalmente com o teatro (a dramaticidade teatral), fortalecendo o conceito de dança-teatro. Ao mesmo tempo, funda o Ballets Jooss, no qual desenvolvia suas próprias produções. Em suas palavras, em 1928, Jooss explica:

Nosso objetivo é sempre a dança-teatro, entendida como forma e técnica de coreografia dramática, preocupada de perto com o libreto, a música, e acima de tudo com os artistas intérpretes. $\mathrm{Na}$ escola e no estúdio, a nova técnica de dança deve ser desenvolvida em busca de um instrumento objetivo não pessoal para a dança dramática, a técnica do balé clássico a ser gradualmente incorporada. ${ }^{9}$ (BERGSOHN; BERGSOHN, 2003, p. 26).

É interessante observar que a proposta de Jooss era na verdade um diálogo entre danças que, para terem um significado, careciam de um assunto concreto. Considerava que, para uma dança dramática ser compreensível sem a utilização das palavras, ela deveria intensificar sua gestualidade. Assim, Kurt Jooss aproxima-se bastante das ideias da dramaturgia noverriana, fazendo com que Garaudy visse seu trabalho como uma "versão século XX do balé de ação" (1973, p. 121).

Sua principal obra, A Mesa Verde ${ }^{10}$, um teatro sem palavras cujo libreto levou cerca de dez anos para ser concebido, ganha notoriedade e reconhecimento de todo o meio artístico dentro e fora da Alemanha, e até os dias de hoje é ainda constantemente apresentada.

Assim, podemos suspeitar que a dramaturgia realizada por Jooss (no caso, A Mesa Verde, única obra a cujo vídeo tivemos acesso - ver referência em bibliografia/filmes) encontra-se na fronteira com a dramaturgia teatral, devido ao seu próprio desejo de manter acesa a teatralidade no coração de sua obra. Teatralidade verificada na configuração de personagens, na qualidade dos movimentos executados em coerência com os personagens criados e na apresentação de uma narrativa linear. Uma dramaturgia construída dentro de uma narrativa com características épico-dramáticas, na qual Jooss equilibra a ideia com a forma (elementos clássicos e modernos). Uma ideia, uma fábula em que podemos ver e "ler", por meio do movimento dançado, uma trama realista. Um encontro entre forma e significado que, assim como em Noverre, ora faz uso da dança, ora da pantomima.

\section{Pina Bausch - Dramaturgia da Subjetividade}

“(...) Pergunto-me como a natureza soube esconder nessa menina tão frágil e tão fina um tal monstro de força e prontidão". (Paul Valéry)
9 "Our aim, is, always, the dance theater, understood as form and technique of dramatic coreografhy concerned closely with libretto, music, and, above all, with the interpretive artist. In school and studio the new dance technique most be developed toward a non-perrsonal objective tool for the dramatic dance, the techinique of tradicional clasical ballet to be gradually incorporated".

10 "Animado por um poderoso sopro de cólera, este balé é uma denúncia satírica da guerra, dos que dela se aproveitam e dos políticos que a geram" (GARAUDY, 1973, p. 121). 
Pina Bausch (1940 - 2009) não escreveu e não gostava de dar entrevistas; e nas raras vezes em que o fez, era frequentemente lacônica, não chegando a objetivar suas respostas. Diante de ávidos entrevistadores, ansiosos por obter respostas referentes aos seus processos de trabalho, criação e construção dos espetáculos, ela se esquivava, apresentando como resposta somente um “... não sei, talvez". Seus segredos nunca foram totalmente revelados. Pina Bausch manteve um mistério em torno de seu fazer, de suas escolhas de material e do modo como os organiza. Responsável pela renovação da dança alemã no final do século XX, juntamente com outras duas grandes coreógrafas - Susane Linke e Rainhield Hoffman -, talvez possamos considerá-la como a maior artista de dança do século XX, e que adentrou o século XXI. Bausch esteve sempre nos surpreendendo, como o próprio ser humano. É nos indivíduos e nas relações criadas e desenvolvidas por eles e entre eles que ela esteve interessada.

Nascida em Solingen, Pina, quando criança, escondia-se debaixo das mesas do café de que seu pai era proprietário na cidade. E parece que a atitude de observar o indivíduo e as relações humanas, repletas de contrates, marcou fortemente a menina, que, quando adulta, materializaria essa atitude em seu trabalho como coreógrafa diretora do Wuppertal Tanztheater, cargo que assume desde 1973. Em suas palavras: "Eu me interesso mais por ver as pessoas na rua, do que ir assistir a um espetáculo de balé" (BAUSCH apud Bentivoglio, s/d, p.3).

A dramaturgia de Pina foi a dramaturgia do homem, da vida cotidiana e de suas relações. Pina teceu diálogos não só entre a dança e o teatro, mas também entre a dança e a ópera, entre os contrastes e sentimentos como popular e erudito, alegria e tristeza, solidão e afetividade, ternura e violência, realidade e subjetividade. Promoveu, ainda, relações dialógicas entre culturas. Muitas vezes, ocorrem diálogos paradoxais que acabam por resultar em um distanciamento. De acordo com Cypriano:

Sob o ponto de vista da encenação, Bausch dialoga com certas propostas de outro alemão, determinante para a cena teatral no século XX: Bertolt Brecht (1898-1956) e seu teatro épico. O efeito de distanciamento Brechtiano como estratégia para evitar o ilusionismo do teatro está presente em várias peças da coreógrafa, como nos momentos em que a luz da plateia é acesa para os bailarinos interagirem com o público (CYPRIANO, 2005, p. 29-30).

A preocupação com a recepção também era parte fundamental da dramaturgia de Pina Bausch. Ela possibilitou ao espectador ser um atuante e desenvolver uma relação ativa dentro do espetáculo. O espectador se torna livre 
para perceber a encenação e chegar a suas próprias conclusões sobre o mesmo. Vejamos o que nos diz mais uma vez Fábio Cypriano, em uma de suas observações sobre o trabalho da diretora:

(...) Bausch chama a atenção do público para sua importância na participação da encenação da dança-teatro, provocando uma equação palco = público; portanto, o que lá se observa refere-se à construção de quem está assistindo ao espetáculo (CYPRIANO, 2005, p. 107).

Mais adiante, o autor reforça a relação entre palco e plateia como parte essencial da dramaturgia bauschiana, fazendo com que o espectador, "imerso entre a delícia e a desgraça, possa emitir o seu juízo":

Assim o espectador das peças de dança - teatro de Pina Bausch deve ter uma função ativa, de criar suas próprias relações e lidar com ambivalências. Ele deve atuar como um "co- autor" (...) (CYPRIANO, 2005, p. 114).

Vale lembrar que essa preocupação com o diálogo entre palco e plateia já era uma grande referência nos fundamentos do expressionismo alemão. Pina foi aluna de um grande mestre, Kurt Jooss, a quem especialmente reverencia. Tendo estudado na escola fundada por Jooss - Essen Folwfang Schulle-, onde ingressa em 1955, Pina assume que essa foi uma grande influência em sua vida artística. As relações dialógicas construídas em seu trabalho certamente foram influenciadas por sua formação lá, pois como ela mesma comenta:

O magnífico daquela escola, ao lado dos meus eminentes professores Kurt Jooss, Hans Züllig, Jean Cébron e outros, era que havia tantas coisas a aprender e todas despertavam a imaginação: a dança clássica e a moderna, o folclore europeu. Particularmente importante era que, na época, todas as seções se achavam sob o mesmo teto: a música, a ópera, a dança, o teatro, fotógrafos, escultores, gráficos, designers de tecidos, tudo isso podia ser mutuamente desfrutado. E nada mais natural que se conhecesse de tudo um pouco. Desde então não consigo ver sem espaço. Vejo também como um pintor ou fotógrafo vê. Essa visão espacial, por exemplo, é um componente bem importante do meu trabalho ${ }^{11}$ (BAUSCH apud NESTROVSKI; BOGÊA, 2000, p. 11).

Assim, Pina nos aponta as possíveis articulações que a dança pode promover, ao valorizar o diálogo entre as disciplinas.
11 Parte do discurso proferido em Bolonha (1999) ao receber o título de doutora honoris causa da Universidade de Bolonha, Itália. 
Assim, Pina nos aponta as possíveis articulações que a dança pode promover, ao valorizar o diálogo entre as disciplinas.

O princípio de seu trabalho, poderíamos também chamar de seu "método" de criação, é baseado em perguntas feitas aos bailarinos. Essas perguntas podem ser respondidas com movimentos, palavras ou por ambos. A improvisação não faz parte desse universo, pois os bailarinos têm tempo para pensar e preparar as respostas que serão apresentadas. Perguntas de toda ordem e natureza povoam esse início de processo. No entanto, o que vai ser escolhido, trabalhado e articulado só mesmo ela sabe. As músicas que acompanham as cenas, muitas vezes, também são bastante variadas e nem sempre criam uma unidade melódica.

Pina cria em cena um caleidoscópio de imagens realistas e ficcionais, expõe contrastes, revela sentimentos, recria a natureza, que se torna um prolongamento dos corpos dos bailarinos. Quando utiliza a palavra, esta vem impregnada por um ritmo que é próprio do movimento dançado e de sua organização. Seus personagens são, na verdade, prolongamentos dos próprios indivíduos (bailarinos), que se transformam em "pessoas cênicas". O universo cênico de Pina revela um diálogo entre dança e dramaticidade. Seus espetáculos apresentam-se normalmente como colagens, como uma colcha de retalhos, salvo alguns poucos, como Café Muller (1978) e A sagração da primavera (1975), que se constituem como espetáculos de dança em sua totalidade. A sagração da primavera de Pina Bausch, segundo Bentivoglio, apresenta-se como uma peça (bailado) "que alcança uma crueza dramática sem laivos de optismo, tendo em conta (como na versão original de 1913) a violência do grupo social perante a donzela (a eleita), predestinada ao sacrifício propiciatório" (BENTIVOLGLIO, 1991, p. 50).

Já sabemos, portanto, que muitos elementos povoam a cena bauschiana, no entanto fica a pergunta: como podemos ter uma sensação de unidade, em um espetáculo, em que a colagem de cenas, músicas, intenções, textos corpóreos e sonoros não se faz segundo uma lógica formal? Como e o que articula a encenação? Como se dá, afinal, essa dramaturgia? Talvez a resposta esteja na declaração da própria diretora: "Há algo muito mais sério do que o público em geral pode ver. Está e está ali, porém não se mostra (...)”12 (BAUSCH apud BENTIVOGLIO; s/d, p.11).

Assim, por mais que revele um corpo mais real que o texto, que perfure intimamente nossas emoções e escancare sentimentos e necessidades de relação entre os seres humanos, Pina Bausch sabe que existe sempre algo que não se mostra, algo que nunca se diz, mas que se percebe, se escuta e atravessa nosso corpo. Assumindo a subjetividade resultante da conexão entre os elementos cênicos que compõem sua obra dramatúrgica, como movimento e palavra, dan-

12 Trecho de entrevista concedida a Leonetta Bentivolglio. 
ça e teatro, realidade e ficção, desejos e expectativas, pulsões, medos, anseios, ternuras, alegrias e sentimentos - algo que existe entre eu e outro -, fragmentando, dissociando gesto e palavra e buscando distanciamentos, Bausch nos apresenta uma dramaturgia de travessias, de ausências, do não revelado.

\section{A CORRENTE AMERICANA - CONTINUIDADE E RUPTURA}

Os Estados Unidos foram, talvez, o país que mais contribuiu para a construção da dança moderna. O país gerou vários criadores, escolas e movimentos, que ampliaram o conceito de dança, a reflexão e a discussão sobre o movimento e seus significados. Nessa geração de criadores, novamente percebemos o aparecimento de rupturas de estilos, em um movimento no qual verificamos claramente a divisão de ramos estéticos.

Dentre os criadores que trouxeram novas percepções sobre a dramaturgia, a composição da cena, o trabalho dos bailarinos e a relação entre forma, expressividade, significados e comunicação, ainda que de forma radicalmente diferente, estão Marta Graham, Doris Humphrey e Merce Cunningham. Contudo, essas rupturas tiveram como base, como ponto de partida, alguns precursores: Isadora Duncan, que já tratamos anteriormente, Ruth Saint Dennis e Ted Shawn, que juntos criaram a Denishawn (Escola e Companhia) ${ }^{13}$. Sobretudo, foi através das sementes lançadas por um "cantor semifracassado" que se alicerçaram as bases da dança moderna no Ocidente. Trata-se do francês François Delsarte ${ }^{14}$, que, embora não se interessasse pela dança, deixa um grande estudo cientificista - "A estética aplicada" -, no qual apontava teorias que se debruçavam sobre as relações conceituais de expressividade e significação dos gestos, sugerindo a observação das relações de intensidades entre sentimento e tradução gestual. As teorias delsartianas influenciaram Isadora Duncan, por intermédio de Geneviéve Stebbins (discípula de Delsarte), com quem estudou, e compuseram o quadro das diferentes disciplinas da Escola Denisshawn.

Saturada de dançar segundo os preceitos dessa escola, acabando por abandoná-la e seguir suas próprias intuições para a construção de uma carreira, a princípio, solo, encontramos uma artista que, para além de bailarina e coreógrafa, foi, como nos lembra Garaudy, "dramaturga de um mundo sem deus e sem unidade humana” (1973, p. 94). Essa artista transformou-se, por meio de um movimento transgressor, em um nome extremamente representativo da dramaturgia na dança moderna:

\section{MARTA GRAHAM - O ESTREITAMENTO ENTRE A DANÇA E O DRAMA} Gostaria de ser conhecida como contadora de histórias (GRAHAM, 1993, p. 182).
13 Antes de mais nada reivindica a ruptura completa com a dança tradicional, o que realiza recorrendo às danças orientais. Não que conheça exatamente as técnicas e os estilos, mas assimila seu espírito; no plano mental, considera que são as liturgias que colocam o dançarino em contato com a divindade (...) No plano técnico, utiliza todo o corpo, considerado o tronco - e não mais os membros inferiores - como ponto de partida de qualquer movimento; busca reforçar a impulsão nervosa situada no plexo solar, de modo que cada músculo esteja imediatamente disponível para traduzir o impulso. Aí está a idéia essencial de toda a técnica moderna" (BOUCIER, 2001, p.263).

14 Teórico de grande importância, nascido em 1811, cantor da Ópera Comique, começou seu trabalho de investigação entre voz e o gesto a partir da perda da própria voz. Usando métodos pouco convencionais, baseados na observação de bêbados, loucos ou moribundos, a eles associou música, partindo para a formulação de uma teoria através da qual criou uma análise de sistematização dos gestos e expressões do corpo humano. Subdividiu-os em três categorias: gestos concêntricos, excêntricos e normais. Estabeleceu também três zonas de expressão: cabeça, tronco e membros (...) Foi também o precursor das primeiras teorias sobre contração e relaxamento, que dariam sustentação aos princípios de uma parte da dança moderna, partindo de uma posição totalmente encolhida para uma extensão plena, que permitisse até a possibilidade de exprimir emoções (...) (CAMINADA, 1999, p. 201). 
Tudo que faço tem uma razão, uma razão muito precisa (GRAHAM, 1993, p. 97).

Creio que se deve ter uma técnica demoníaca (GRAHAM, 1993, p. 177).

(...) Mas a arte é eterna, pois revela a paisagem interior, que é a alma do homem (GRAHAM, 1993, p. 11).

O movimento nunca mente (GRAHAM, 1993, p. 12).

Seu corpo diz o que as palavras não podem dizer (GRAHAM, 1993, p. 15).

Nesse recorte de frases extraídas de seu livro Memórias do sangue, Marta Graham (1894 -1991) nos dá pistas sobre sua necessidade urgente de expressão, sobre seu desejo de dançar os anseios humanos. Graham dançou a realidade de seu tempo, cultivou suas raízes, valorizou suas memórias e seu país. Acreditou no homem, preservou sua liberdade e seus instintos. Dramática, intensa, explosiva, brusca e vigorosa, de forma expressionista dançou a agonia, o sonho e o horror, as misérias e as glórias da humanidade, o prazer e o êxtase. Criou sua própria técnica, revelando por meio dela suas paixões, repulsas e sua poesia. Segundo Caminada: “(...) foi, sem dúvida, o nome mais importante da dança moderna” (1999, p. 225).

Se analisarmos suas criações à luz da dramaturgia, veremos que Graham contribuiu, em suas composições, para dramaturgia do movimento dançado, sobretudo, com um corpo que deve ser significante, como tradutor da força das emoções. O movimento/corpo em sua dança é um instrumento de narrativas cujas ações se encontram apoiadas nas pulsões emotivas, materializadas em diversas obras criadas pela coreógrafa-dramaturga. Essas obras, conforme nos indica Garaudy, inspiravam-se em outras artes como:

(...) a pintura de Picasso, as pesquisas abstratas e os livros de Kandinsky sobre O Espiritual na Arte, a música de Bela Bartok, o surrealismo de T.S. Eliot, e também a psicanálise de Freud e de Jung (GARAUDY, 1973, p. 95).

A partir de inspirações como as citadas acima, Graham dialogou com inúmeros temas, como os mitos, tanto gregos (Electra, Clitemnestra, Édipo e Jocasta, Teseu, Circe, o Minotauro) como indígenas e tradicionais (Night Chant, Appalachian Spring, Frontiers). Graham, que possui uma obra coreográfica imensa, dialogou ainda com poemas, temas religiosos, personalidades femi- 
ninas, as relações entre os sexos, protestos contra a violência (referência à ditadura espanhola de Franco), a barbárie de Guernica e também com o próprio corpo e suas obsessões, como no célebre solo "Lamentations".

Em suas "manifestações" coreográficas, percebemos a evidência de um movimento repleto de intenções, na tentativa de revelar as profundidades da alma do ser, levando-a a expressar conceitos para além da palavra. Para atingir seus objetivos, Marta Graham cria sua própria técnica, base da forma de seus desenhos corpóreos. Nessas formas, o corpo retrata suas tensões, ilustrado por torções num jogo permanente de oposições, dilatações, contrações e relaxamentos. A idéia-movimento da expansão e do recolhimento pontua a síntese de sua técnica. As paradas bruscas, a interrupção do movimento, eram também uma marca significativa em sua obra. Graham desejava que a ação de interromper o movimento fizesse com que o espectador desse continuidade ao mesmo, imaginando sua execução. Movimento que, com base nas leis vitais da respiração (inspiração, pausa, expiração, pausa), unificava no corpo o próprio ato de viver. Graham relacionava, assim, o ato de dançar com o ato de viver (encontro de fluxos). Um corpo que traçava linhas de forças, de construção e tensões internas. Podemos resumir a concepção dos movimentos de Graham, segundo Garaudy, em quatro princípios:

1) A metamorfose do ritmo;

2) A intensificação dinâmica;

3) A relação gravitacional;

4) A totalidade.

Na articulação desses elementos, objetivados dentro da exposição de um tema e aliados, na maioria das vezes, à simbolização de uma história, ou em diálogo com esta, Graham constrói suas narrativas dilacerantes, apaixonadas, viscerais e vivas. Não podemos deixar de lembrar que a composição cenográfica também esteve sempre presente na obra de Graham, contribuindo para o caráter simbólico de suas criações. Ela encontrou e desenvolveu parcerias não só com artistas plásticos, mas também com escritores e músicos. Embora tendo na dramaticidade, nas memórias emotivas e na caracterização de personagens os elementos constitutivos de suas encenações, poderíamos dizer que, sob seu ponto de vista, a dramaturgia de sua dança se aproxima da dramaturgia teatral. Nas palavras de Garaudy:

Para Marta Graham, a dança e o teatro são uma coisa só. Primeiro porque, para ela, o teatro não é espetáculo é participação (...) (GARAUDY, 1973, p. 97). 
Deduzimos, assim, a construção de uma dramaturgia narrativa, não organizada pela palavra nem mesmo apenas pelo movimento, mas, sobretudo, uma dramaturgia das emoções. Emoções que orientam a organização não só dos desejos, como também do sentido objetivado. Emoções que impulsionam, atravessam o corpo e que, à medida que são reguladas e articuladas em suas intensidades, revelam o movimento. A dramaturgia de um corpo tradutor de emoções e histórias urgentes de expressão, pulsantes, e que, por fim, celebram A VIDA.

\section{DORIS HUMPHREY - "ENTRE MUNDOS MORTOS"}

Assim como Marta Graham, Doris Humphrey (1895-1958) desligou-se da Denishawn. Insatisfeita com a falta de autenticidade com que Saint-Denis e Ted Shawn apropriavam-se dos movimentos de outras culturas e tradições, expressando-as superficialmente, Doris aliou-se a Charles Weidman ${ }^{15} \mathrm{e}$ criaram sua própria companhia.

Embora tenha tido menos visibilidade do que Graham, em razão de seu caráter introvertido, compartilhava com ela algumas afinidades para criar suas danças, dentre elas o desejo de expressão calcado nas necessidades do ser humano, de sua nação e de seu tempo. Dedicou-se mais ao trabalho de formação, não deixando, contudo, de criar uma obra extensa (em torno de 50 coreografias). Humphrey também desenvolveu danças em permanente diálogo com diversos temas, como o silêncio ("Water Study" - 1928), o misticismo ("Passacale e fuga em dó menor " - 1938) e poemas "Lament"). A música também teve um caráter relevante em sua obra, utilizada ora para criar um ambiente, um clima para que o movimento se instalasse, ora para contrastar com o mesmo. Não só as inquietações e os problemas do homem moderno ocupam espaço em sua obra, mas também reserva lugar à abstração, retratada na peça coreográfica "Canonade" (1944).

Analisando dramaturgicamente suas composições, verificamos que Doris Humphrey utilizou-se da estratégica da simultaneidade ao compor "Inquest". Segundo Boucier:

(...) Inquest, último balé de que participará e que comporta dois quadros simultâneos: o que descreve os fatos e o que exprime os estados emocionais decorrentes (BOUCIER, 2001, p. 268).

Criou uma técnica genuína, conhecida como "fall-recovery" (queda e recuperação), conceituada por ela como um "drama muscular". Nessa técnica percebemos a concentração do movimento fundamentada no equilíbrio, na ação de ceder o peso do corpo à gravidade para logo em seguida recuperar sua verticalidade. Assim, o dançarino trafega entre duas oposições, construindo um
15 “(1901-1975) Interessante e original neste artista é o fato de ele ser mais um homem de teatro do que um dançarino, tendo desviado, assim, a dança moderna para as necessidades cênicas. Antes dele, Ruth Saint-Denis e Ted Shawn tiveram a tendência de expor estados emocionais de maneira, de certa forma, linear. Sob a influência de Weidman, a geração saída da Denishawn associará a ação dramática à pintura dos estados d'alma, pois a teatralização reforça a expressão do corpo, tornando-a mais compreensível para o público" (BOURCIER, 2001, p. 265). 
sentido revelado como a própria ação de viver. Viver, dançar entre oposições, dentro de um fluxo que circula em todo ser humano. $O$ ato de cair e se recuperar traz dramaticidade ao movimento e, por consequência, leva à organização de sequências rítmicas motoras que se formam na inter-relação entre o corpo e o espaço. Contudo, Humphrey não se contentou em fundamentar seu fazer apenas nesses princípios, e desenvolveu uma reflexão valiosa, que contribui para ampliar as bases desta pesquisa. Classificou os gestos (sociais, funcionais, rituais e emocionais), distinguiu movimentos (simétricos e assimétricos, angulosos e arredondados) e fundamentou os elementos de sua composição coreográfica (motivação, ritmo, dinâmica e desenho).

Sobre a conceituação gestual de Humphrey, Garaudy afirma que "os gestos emocionais, os mais importantes para o bailarino, são os gerados espontaneamente por nossos sentimentos" (GARAUDY, 1973, p. 123).

Mesmo que essa conceituação estivesse na base de sua criação, é a própria Humphrey que a amplia, por entender que o gesto não traduz um sentimento na sua inteireza, pois a dança não é mímica. Assim, ela encontra na qualidade do movimento a resposta para que a transformação aconteça e o movimento não seja simplesmente representativo e superficial. Humphrey acredita que o atuante deve não somente imprimir ao movimento força interior, mas criar a conexão entre essa força e “(...) o ritmo voluntário de sua vida, criadora e militante, em favor do advento do homem humanizado" (GARAUDY, 1973, p. 125).

Quanto aos elementos de sua composição coreográfica-dramatúrgica, verificamos que o ritmo presente no ato de cair e recuperar-se, movimento presente nas ações humanas, proporciona um preenchimento do espaço entre o que ela chama de "dois tempos mortos". - um tempo de inação na vertical e um tempo de abandono, surgido do efeito da queda. O entre-lugar está mais uma vez presente no conceito de dramaturgia.

Um segundo elemento a ser notado é o dinamismo, isto é, "as mudanças de intensidades" (GARAUDY, 1973, p. 128). Aqui, assim como já mencionado quando tratamos de Laban, as dinâmicas têm um papel central na tessitura dramatúrgica, pois veiculam diferentes intensidades que, conforme articuladas e reguladas, possibilitam diferentes significados e compreensões do objetivo, da ideia proposta. As dinâmicas são descargas de forças que podem ser conduzidas de diferentes maneiras, possuir diferentes acentos, sugerir prolongamentos e pausas bruscas. A diversidade de tônus que pode ser apresentada no movimento produz diferentes significados. Dentro da utilização da dinâmica, Doris Humphrey distingue os movimentos, como, por exemplo, os arredondados, os circulares, os agudos. Segundo Garaudy: 
Alguns movimentos se prestam mal a esta descarga de forças: a curva, por natureza, é doce e contínua, e mais ainda os movimentos circulares, assim como as oscilações dos ombros e do quadril. Tais movimentos só podem ser marcados por um acento se forem cortados por uma parada brusca. A variedade desta gama permite comunicar os sentimentos: um movimento dinâmico com seus acentos bruscos, é estimulante; um movimento lento e contínuo é calmante (GARAUDY, 1973, p. 128).

O desenho (simétrico ou assimétrico) é o próximo elemento a ser observado, tendo em vista que sua finalidade é permitir que a emoção se tornasse visível. Para Doris, é da experiência no cotidiano que ele surge, bem como dos hábitos que o corpo recebe e absorve. Os desenhos, em suas diferentes formas e perspectivas, oferecem-nos sensações diferenciadas: da calmaria ao embate, da quietude à convulsão, evoluindo no tempo e no espaço da representação. Pensando que sua dança alojava-se no espaço convencional (palco), Humphrey, segundo Boucier, "adapta as noções cênicas propostas por Gordon Graig ${ }^{16}$ à dança” (2001, p. 271), ou seja, direciona seu olhar para a relação significativa do palco com o corpo do atuante. Conforme a localização do bailarino em cena, seja nos cantos, ao centro ou nas diagonais do palco, conforme posiciona seu corpo de frente ou de costas ou pela direita ou esquerda deste, no proscenium ou ao fundo do mesmo, um novo significado vem à tona e, por sua vez, estabelece relações com a força dos gestos. Assim, o palco é também fundamental para a construção e o desenvolvimento de uma dramaturgia.

Doris Humphrey tem importância fundamental para o estudo da dramaturgia, não somente pelo fato de ter sistematizado sua teoria de composição coreográfica, mas também por ter elaborado, assim como Laban, um sistema de notação de movimentos. Não podemos deixar de lembrar seu primeiro princípio, a base de todos os elementos anteriormente citados na construção de uma obra que dance: a motivação. Esta representa a essência, "a alma de toda composição coreográfica" (GARAUDY, 1973, p. 127).

\section{Merce CunNHinghaM - Dramaturgia dA "NÃO-DRAMATURGiA" OU DRAMATURGIA DO ACASO, DO CORPO, DO MOVIMENTO, DA AÇÃO}

\section{PURA E DANÇANTE}

"Não é o que estamos vendo? - Que queres de mais claro sobre a dança, além da dança nela mesma?" (Paul Valéry)
16 Edward Gordon Graig (1872-1966). Ator, encenador e cenógrafo inglês, cuja concepção teatral foi caracterizada por seu peculiar antinaturalismo e pela pureza cenográfica. Foi uma das personalidades mais decisivas para a história do teatro ocidental, promovendo uma notável renovação dos palcos europeus no século XX. Foi um dos pilares do chamado simbolismo teatral. Criador do conceito-imagem "super marionete", onde vislumbrava um “(...) ator livre do ruído da emotividade que nada interessa ao trabalho da representação" (GRAIG, 1942). Disponível em www.artes.com/ reflexões/ref 57 - htm. Gordon Graig in "Da arte do teatro" (1942). 
Merce Cunningham (1919-2009)) inaugura um novo tempo, abre outras portas e rompe com os elementos que fundamentaram a dramaturgia da dança anterior a ele. Propõe desligamentos, novas operações, introduz novos elementos na composição dançante. Acaba por influenciar um novo pensamento que surgiria na dança, a partir dele: o pós-modernismo, desenvolvido, sobretudo na América do Norte, mas que também influenciou criadores europeus. Verifiquemos as contribuições de Cunningham para esse novo modo de pensar a dança.

Merce Cunningham é um exemplo claro de ruptura no universo da dança. Começa sua carreira pelos estudos de dança, atravessa os estudos de formação em teatro (ator), mas termina por voltar à dança, sob a direção de Marta Graham, atuando em sua companhia por seis anos. É nesse momento que a ruptura se faz. Cunningham, sob a influência direta do músico John Cage, rompe com as estruturas vigentes da dança moderna: dramaticidade, teatralidade, representação, personagens, linearidade narrativa, lógica, intenções, coordenação de seqüências, sentido de continuidade, centralização espacial. Rompe, enfim, com toda a expressividade que fosse além daquela contida no próprio movimento. Assim, nega o psicologismo, o sentimento, a perspectiva dramática como acionadores do movimento, estruturas básicas do modelo criado por Graham.

Cunningham dá-nos a impressão de alguém que quer se lavar e se livrar de qualquer artifício, qualquer tema ou assunto que embase uma composição, a não ser o próprio movimento, o elemento norteador de sua composição. Contudo, não podemos deixar de observar, de acordo com a perspectiva desenvolvida até aqui, que as relações de encontro e diálogo e os entre-lugares não deixarão de existir. Merce pode não dialogar, mas o encontro permanece, e este, por sua vez, cria novas conexões. Conexões materializadas no acaso, no indeterminismo, no entre-lugar das intensidades, no próprio corpo e em seus movimentos, na apropriação de novos espaços cênicos, na não-relação entre dança, música e cenário. Os elementos constitutivos da dramaturgia de Cunningham são aleatórios, cabendo ao espectador criar sua unidade, organizar de forma livre, apreender seu sentido e interpretá-lo como bem quisesse. Assim, sua obra é caracterizada como obra aberta, gerando, por sua vez, uma dramaturgia aberta, como nos informa Rodrigues:

Como obras abertas, suas coreografias provocavam inúmeras e diversas leituras. Como não havia muitas vezes um foco específico, mesmo espacialmente, a plateia poderia fazer conexões e interpretação interessantes (RODRIGUES, 2005, p. 108).

Não é possível falarmos de Cunningham sem falarmos do compositor John Cage e de suas investigações e proposições musicais. É Cage quem lança as 
ideias que serão absorvidas e desenvolvidas por Cunningham. Van Langendonck, falando a respeito de Cage, afirma que "sua relevância pode ser encontrada no entendimento da temporalidade, nas relações de lei e acaso e na adoção de movimentos observados no cotidiano" (2004, p. 31). Juntos criaram uma longa parceria que durou mais de 50 anos. Cage teve um papel imenso não só na vida e na dança de Merce, como também na história da música e da concepção cênica. Ainda segundo Langendonck:

Cage foi a inteligência que influenciou o pensamento da pós-modernidade na América do Norte. Em seus cursos, encorajava os alunos a usar instrumentos não convencionais ou a combiná-los com instrumentos convencionais, instruía sobre notação, propriedades de som, como alterá-las e como controlar diferentes situações de tempo (...) (LANGENDONCK, 2004, p. 31).

Dentre as investigações, sugestões e proposições feitas por John Cage e assimiladas e ampliadas por Merce estão: a independência entre as artes, a não interpretação da música, o acaso como elemento norteador (fruto do estudo do I Ching - Livro das Mutações). Essas ideias levam o coreógrafo a trabalhar sob a forma de estruturas que vão agir e se interpenetrar livremente no espaço e no tempo. Assim, Merce distingue novos conceitos, que ampliam e desestruturam os conceitos vigentes da época, pelo menos no Ocidente. Diante do modo como operam as danças de Cunningham, desprovidas de conteúdo emocional e dramático, dissociando música e dança, permitindo que o olhar não busque a mesma lógica, perguntamos: como se constituiria então o sentido de unidade de suas "performances", como se constituiria a dramaturgia, onde estariam os seus nexos?

Percebemos que no manifestar da própria desarticulação dos elementos da cena ou na própria articulação de movimentos encontraremos o sentido de unidade. Trata-se de uma dramaturgia que o espectador vai construir por sua conta e risco, como o próprio Cunningham afirmava ao relacionar sua dança com aleatoriedade dos fatos da vida. Segundo van Langendonck:

A independência entre os elementos do espetáculo, que caracteriza o trabalho desse artista, revela-se na unidade do espetáculo. Unidade essa que se assemelha à natureza, que, em sua diversidade, aparece-nos maravilhosa e uma (LANGENDONCK, 2004, p. 55).

Merce acreditava que o jogo gramatical aleatório (vocabulário corporal com sua própria lógica, vazia de conteúdo, despido da experiência e da significação emocional), realizado pelo próprio movimento, que extrai unicamente, 
segundo Gil, "de si mesmo sua energia” (GIL, 2005, p. 40), permitiria ao espectador traçar suas próprias analogias.

Observamos, por fim, que, em suma, Cunningham nos apresenta um movimento que é impulsionado e materializado na própria ação de dançar, configurada no corpo dançante. Encontro entre movimento e corpo que, a priori, não significa nada mais que a própria manifestação deste no tempo e no espaço. Para Gil, a imanência é o plano guia dessa dramaturgia. Ainda segundo Gil: Plano de imanência de Cunnhingham desdobrava-se apenas na esfera da arte. Para uma geração que não mais queria a imanência porque estava na imanência (da arte à vida), tornava-se inevitável que o estilo Cunningham surgisse como um objeto a recusar, arrastando consigo o que não estava de acordo com o real de então: a disciplina dos corpos, o "glamour", o espetáculo, no fundo, o extremo profissionalismo dos bailarinos identificado como o extremo elitismo de um estilo elegante, ainda balético, muito puro e sublime (GIL, 2005, p. 150).

\section{Alinhavando}

Neste pequeno percurso histórico ocidental, verificamos que a dança passou da imitação da natureza para a criação de um modelo de tradução da natureza humana, para logo em seguida negar esse modelo, como o faz Merce Cunningham. Mesmo Cunningham, porém, ainda se encontra dentro de um modelo: por mais que tenha se deslocado do cânone da dança moderna, ele não rompeu com os cânones da arte. Percebemos, assim, uma evolução da dramaturgia na dança, que se desenvolveu de forma inerente à mesma e seus processos criativos.

Destarte, vimos que, mesmo em continentes diferentes (América do Norte e Europa), a inquietude criativa se manteve fazendo com que as perguntas se ampliassem. Em um primeiro momento (pré-Cunningham e Pina Bausch), o bailarino torna-se o centro da dramaturgia. Os sentimentos e as emoções humanas urgem por exprimir-se, e, juntamente com o simbolismo de uma realidade, de um tempo-mundo e de uma época, compõem os pontos estruturadores das encenações. Após esse período, Cunningham, como já vimos, encontra no próprio movimento o mecanismo e o apoio para "ordenar suas danças", enquanto Pina Bausch potencializa a energia das ações humanas a tal ponto que uma carícia também pode ser como uma dança.

\section{REFERÊNCIAS BIBLIOGRÁFICAS}

ARNHEIM, Rudolf. Arte e Percepção Visual. São Paulo: Pioneira, 1980. BENTIVOLGIO, Leonetta. Dialogando com Pina Bausch. In: Escena Crítica. 
Publicação da Associação de Críticos Teatrais do Uruguai, (s/d).

BERGSOHN Isa Partsch e BERGSOHN Harold. The Makers of Modern Dance

in Germany. USA: Princenton Book Company, Publishers, 2003.

BOURCIER, Paul. História da Dança no Ocidente. São Paulo: Martins Fontes. 2001. CAMINADA, Eliana. História da Dança - Evolução Cultural. Rio de Janeiro:

Sprint, 1999.

CARDINAL, Roger. O Expressionismo. Rio de Janeiro: Jorge Zahar, 1984.

COLOMÉ, Delfin. Pina Bausch: um volumen que envuelve la vida. In: El indiscreto encanto de la danza, s/d, p. 83-90.

CYPRIANO, Fábio. Pina Bausch. São Paulo: Cosac Naify, 2005.

CYPRIANO, Fábio. Pina Bausch ergue sua babel. Revista Bravo. São Paulo, n.

13, p. $124-129,1998$.

FERNANDES, Ciane. Pina Bausch e o Wuppertal Dança-Teatro: Repetição e transformação. São Paulo: Hucitec, 2000.

GARAUDY, Roger. Dançar a Vida. Rio de Janeiro: Nova Fronteira, 1980.

GIL, José. Movimento total: O corpo e a dança. São Paulo: Iluminuras Ltda, 2005. GRAHAM, Martha. Memória do Sangue. São Paulo: Siciliana, 1993.

HODGSON, John e PRESTON-DUNLOP Valerie. Rudolf Laban: an introduction

to his work \& Influence. Plymouth: Northecote House, Publishers Ltd., 1990. HOGHE, Raimund \& Weiss, Ulli. Bandoneon - Em que o tango pode ser bom

para tudo? Trad. Robson Ribeiro \& Gaby Kirsch. São Paulo: Attar, 1989.

HOGHE, Raimund. Uma carícia também pode ser uma dança. In: Revista Bravo, São Paulo, 2004, pp 20-25.

LABAN, Rudolf - ULLMANN Lisa (org) - Domínio do movimento. São Paulo: Summus Editorial, 1978.

LANGENDONCK, Rosana Vaz. Merce Cunnhingham Dança Cósmica: acaso, tempo, espaço. 2004.

MOMMENSOHN, Maria e PERRELLA, Paulo (org). Reflexões sobre Laban, o mestre do movimento. São Paulo: Summus Editorial, 2006.

MONTEIRO, Mariana. Noverre: cartas sobre a dança. São Paulo: Falusp, 1998. NESTROVSKI, Arthur e BOGÊA, Inês. $O$ gesto essencial. In: A arte total de

Pina Bausch. São Paulo. Caderno Mais: Folha de São Paulo, 2000, p. 4-15. PAVIS, Patrice. Dicionário de Teatro. São Paulo: Perspectiva S.A, 1999.

A Análise dos Espetáculos. São Paulo: Perspectiva S.A, 1996.

RENGEL Lenira. Dicionário Laban. São Paulo: Annablume Editora Comunicação, 2003.

SILVA, Eliana Rodrigues. Dança e pós-modernidade. Salvador: Edufba, 2005. THORNTON, Samuel. Laban's theory of movement: a new perspective. Boston:

Plays, ING, 1971. 
VALÉRY, Paul. A Alma e a Dança e outros diálogos. Rio de Janeiro: Imago, 1996.

17 (Acervo de Arnaldo Leite Alvarenga).

\section{VÍDEOS}

BAUSCH, Pina. O lamento da Imperatriz

\section{Sagração da Primavera}

Café Muller

Rudolf Von Laban - Recriações Coreográficas de 1923 a 1928. Direção: Valerie Preston Dunlop. Londres: Laban Centre, 1992.

Dança do Século. Documentário sobre a história da Dança.

WIGMAN, Mary. Mein leben ist tanz. Roteiro e direção: Ulrich Tegeder. Produção: nter-Nationes, $\mathbf{s} / \mathbf{d} .^{17}$

JOOSS, Kurt. Der grune tisch ein totentanz. Folkwangballet-WDR, Deutscheland, s/d."

\section{SITE}

www.artes.com/reflexões/ref 57 - htm. Gordon Graig in Da arte do teatro (1942). 